\title{
TEST REQUIREMENTS OF LOCOMOTIVE FUEL TANK BLUNT IMPACT TESTS
}

\author{
Karina Jacobsen \\ Michael Carolan \\ Patricia Llana \\ Volpe National Transportation Systems Center \\ United States Department of Transportation \\ Cambridge, Massachusetts, USA
}

\section{ABSTRACT}

The Federal Railroad Administration's Office of Research and Development is conducting research into passenger locomotive fuel tank crashworthiness. A series of impact tests are planned to measure fuel tank deformation under two types of dynamic loading conditions. This paper describes the test requirements for the preliminary tests in this series - a blunt impact of conventional locomotive fuel tanks.

Current design practice requires that Tier 1 locomotive fuel tanks have minimum properties adequate to sustain a prescribed set of static load conditions [1]. In accidents, fuel tanks are subjected to dynamic loading, often including a blunt or raking impact from various components of the rolling stock or trackbed. Current research is intended to increase understanding of the impact response of fuel tanks under dynamic loading. Utilizing an approach that has been effective in increasing the structural crashworthiness of passenger railcars, improved strategies can be developed that will address the types of loading conditions which have been observed to occur in a collision or derailment event. The improvement strategies developed by this research program can then be applied to alternative fuel tank designs, such as diesel multiple unit (DMU) tanks.

This paper describes test requirements for conducting two preliminary tests. These tests are referred to as preliminary because they will be used to evaluate the loading setup and instrumentation planned for the larger series of tests. These preliminary tests will evaluate a blunt impact on the bottom surface of two conventional passenger locomotive fuel tanks. The test articles chosen for the preliminary tests are fuel tanks removed from two retired EMD F-40 locomotives. While these fuel tanks do not reflect the current state of locomotive fuel tank manufacturing or design, they are suitable for means of these tests.

Each fuel tank will be mounted to a crash wall and impacted on its bottom face by an impact cart with a rigid impactor at a prescribed velocity. The first set of tests is designed to measure the deformation behavior of the fuel tanks. These tests are planned to result in puncture of the bottom surface of each fuel tank. The preliminary tests are targeted for October 2013 at the Transportation Technology Center (TTC) in Pueblo, Colorado.

Following this first series of impact tests, a second set of dynamic impact tests is planned to be conducted. This second set will include both blunt and raking impact conditions on conventional fuel tanks, DMU fuel tanks and fuel tanks incorporating improved strategies for impact protection. Lessons learned during the preliminary two tests will be applied during the second set of tests to improve the performance of those tests. Fuel tank research is being performed to determine strategies for increasing the fuel tank impact resistance to mitigate the threat of a post-collision or post-derailment fire.

\section{INTRODUCTION}

Fuel tank crashworthiness research is being conducted as part of the Federal Railroad Administration's (FRA's) Equipment Safety Research program. Crashworthiness research efforts follow the methodology shown in Figure 1 which begins with developing a baseline measure of existing design performance for a given scenario and extends to develop improvements for enhancing safety performance for that scenario. 


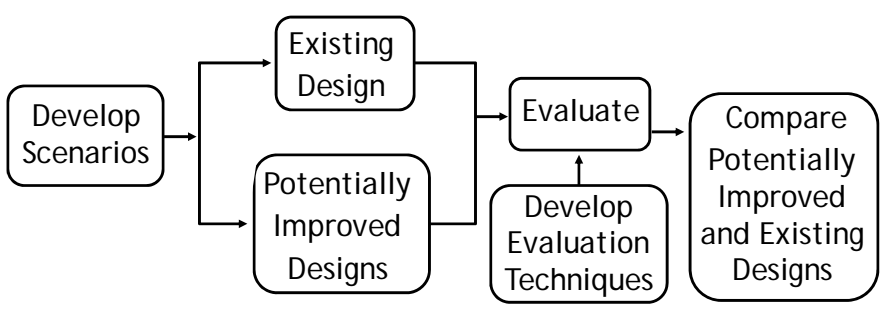

Figure 1. Flow Diagram, Crashworthiness Research Methodology

Collision history shows that in the event of a fuel tank rupture during a train collision or derailment, fire may result which presents additional threats to the survivability of passengers and crew as they egress from the collision wreckage. Further investigations into the types of rail incidents in the U.S. in which fuel tank ruptures occur, highlight scenarios and resultant loading conditions that lead to fuel tank ruptures. The table below summarizes the results of an accident survey conducted under FRA research [2]. Each scenario can be categorized by its resultant loading type and there are two general loading conditions leading to punctures: blunt impacts and raking impacts.

Table 1. Locomotive Collision Scenarios and Related Fuel Tank Impact Modes

\begin{tabular}{|l|l|l|}
\hline & Collision Scenario & Collision Mode \\
\hline 1 & $\begin{array}{l}\text { Impact with Surrounding Railcar } \\
\text { Component }\end{array}$ & Blunt Impact to End of Tank \\
\hline 2 & Oblique Impact with Another Railcar & $\begin{array}{l}\text { Raking of Side of Tank OR } \\
\text { Blunt Impact to Side of Tank }\end{array}$ \\
\hline 3 & $\begin{array}{l}\text { Rollover and Impact with Another } \\
\text { Railcar }\end{array}$ & Blunt Impact to Bottom of Tank \\
\hline 4 & Grounding & $\begin{array}{l}\text { Raking of Bottom or Side of Tank OR } \\
\text { Blunt Impact to Side of Tank }\end{array}$ \\
\hline 5 & Impact with Rail or Other Object & Blunt Impact to Bottom of Tank \\
\hline
\end{tabular}

This research focuses on evaluating dynamic impact conditions for fuel tanks and investigating how fuel tank design features (such as baffle placement) affect the collision performance of the tank. Research activities include analytical modeling of fuel tanks under dynamic loading conditions, dynamic impact testing of fuel tank articles, and recommendations for improved fuel tank protection strategies.

Understanding the dynamic response of fuel tanks under idealized impact conditions will inform the evaluation of designs that are more puncture resistant. A series of fullscale tests is planned to simulate blunt and raking impacts of various fuel tank designs. Table 2 shows the target timeline for the proposed testing.
Table 2. Future Fuel Tank Test Plans

\begin{tabular}{|l|c|c|c|c|}
\hline \multirow{2}{*}{} & \multicolumn{2}{|c|}{ Conventional Fuel Tank } & \multicolumn{2}{|c|}{ Alternative Designs } \\
\cline { 2 - 5 } & $\begin{array}{l}\text { Passenger } \\
\text { Locomotive }\end{array}$ & DMU & $\begin{array}{l}\text { Passenger } \\
\text { Locomotive }\end{array}$ & DMU \\
\hline Blunt & Fall & Winter & Summer & Winter \\
Impact & 2013 & 2014 & 2015 & 2016 \\
\hline Raking & Summer & Fall & Fall & Summer \\
Impact & 2014 & 2014 & 2015 & 2016 \\
\hline
\end{tabular}

One key output of this series of full-scale tests is to understand the deformation pattern of a fuel tank under dynamic impact loads. The particular design features of the fuel tank affect the behavior of the tank when loaded. Through testing, the dynamic response of the tank can be observed, measured and documented. Comparing the test results of pretest modeling and analyses helps to refine the models. Models can then be used to vary parameters both of the tank features and the impact conditions to better understand the range of impact behavior of that specific tank design. For example, the impact location can be varied to examine the tank's response to impacts at various places on the surface of the tank. Extrapolations can then be made for other fuel tank designs which may include different design features, e.g. size, shape, baffle configuration, stiffeners, material properties, etc.

The purpose of testing conventional fuel tanks is to establish a baseline level of performance and to characterize the loading parameters that deform a tank and can lead to the undesirable consequence of fuel tank rupture. This paper focuses on the testing scheme and requirements laid out for the first set of tests on conventional passenger locomotive fuel tanks. A blunt impact condition will be simulated in each test.

\section{BLUNT IMPACT TEST SCENARIO}

The preliminary testing of conventional fuel tanks will be conducted in fall 2013 at the Transportation Technology Center (TTC) in Pueblo, Colorado. A blunt impact will be imparted to two fuel tank designs. Each test will simulate a rigid impactor striking the bottom surface of the tank. The impact speed will be chosen to deform the tank sufficiently to measure the forcedeflection characteristic of the tank.

\section{Objective}

The first two impact tests are being performed to inform and guide the testing plans for the subsequent tests. Because the fuel tank tests will be destructive tests, it is important to have a thorough understanding of the test setup, instrumentation needs, and test parameters before conducting tests on DMU fuel tanks or tanks of an alternative design. To that end, the first tests will be conducted as "shakedown" tests of the overall test setup and instrumentation.

The key objective of the impact testing of fuel tanks is to examine the gross response of the fuel tanks to a given impact type. For the blunt impact tests the objective is to characterize each fuel tank's deformation behavior when impacted on the bottom sheet. The overall approach to characterizing the deformation behavior includes: 
1. Apply a blunt, dynamic load to the bottom surface of a fuel tank to deform the fuel tank.

2. Measure the force-deflection behavior of the tank with specified instrumentation.

3. Record mode of deformation with high-speed and conventional video cameras.

\section{Test Setup}

The impact scenario for the preliminary tests is illustrated schematically in Figure 2. The target area of the locomotive fuel tank is the center of the bottom sheet. The tank will be mounted to a vertical test wall at TTC. A rail cart will be fitted with a rigid 12-inch by 12 -inch impactor. This impact cart will roll along the tracks to impact the bottom of each fuel tank at the target speed, imparting the desired impact force.

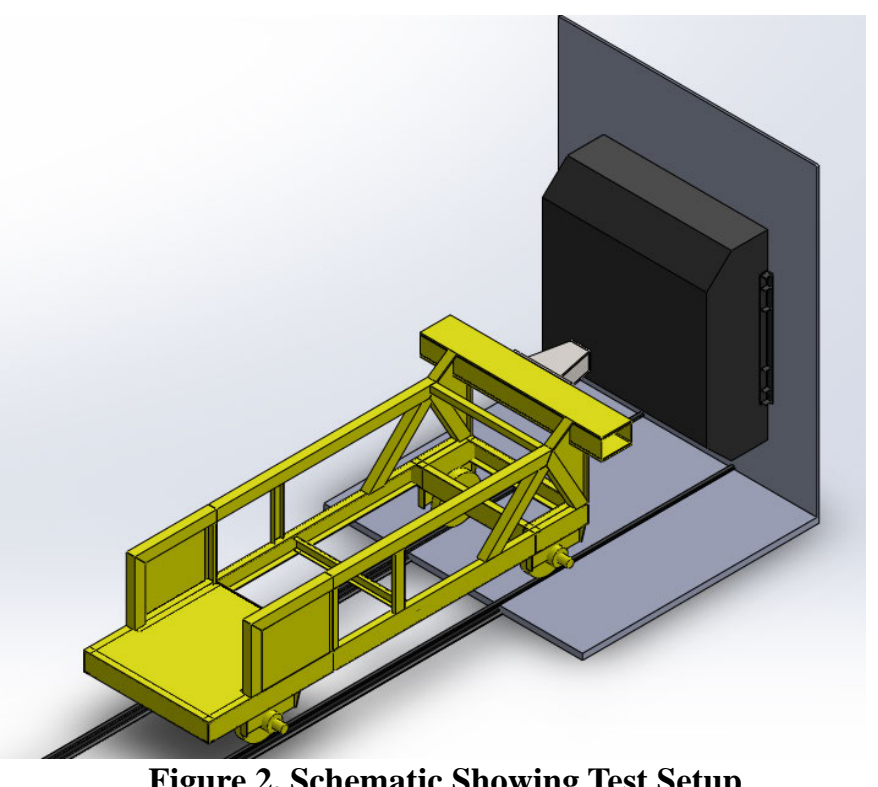

Figure 2. Schematic Showing Test Setup

\section{TEST SPECIMENS}

Two previously-used locomotive fuel tanks will be used in these preliminary tests. These tanks are from F-40 type locomotives and are referred to as locomotives 202 and 232. While the locomotives are similar and previously used in passenger service, the two fuel tanks taken from these locomotives have different designs details (i.e. shape and internal baffle layout).

These two fuel tanks are not representative of the state-ofthe-art in current locomotive fuel tank design or construction. However, these fuel tanks are suitable test articles for the preliminary evaluation of the overall test setup. These tanks will provide the types of data that are sought from the impact tests of alternative-design fuel tanks. As these tanks were collected from locomotives already donated to FRA and available at TTC, the overall cost and schedule for the preliminary tests can be minimized, compared with attempting to purchase new fuel tanks for a new type of test.

The tanks have been removed from the underframes of the locomotives as part of the preparations for the impact tests. Each fuel tank has a listed capacity of 1800 gallons. As seen in
Figure 3, tank 202 has a roughly trapezoidal-cross section, while tank 232 has a rounded shape.

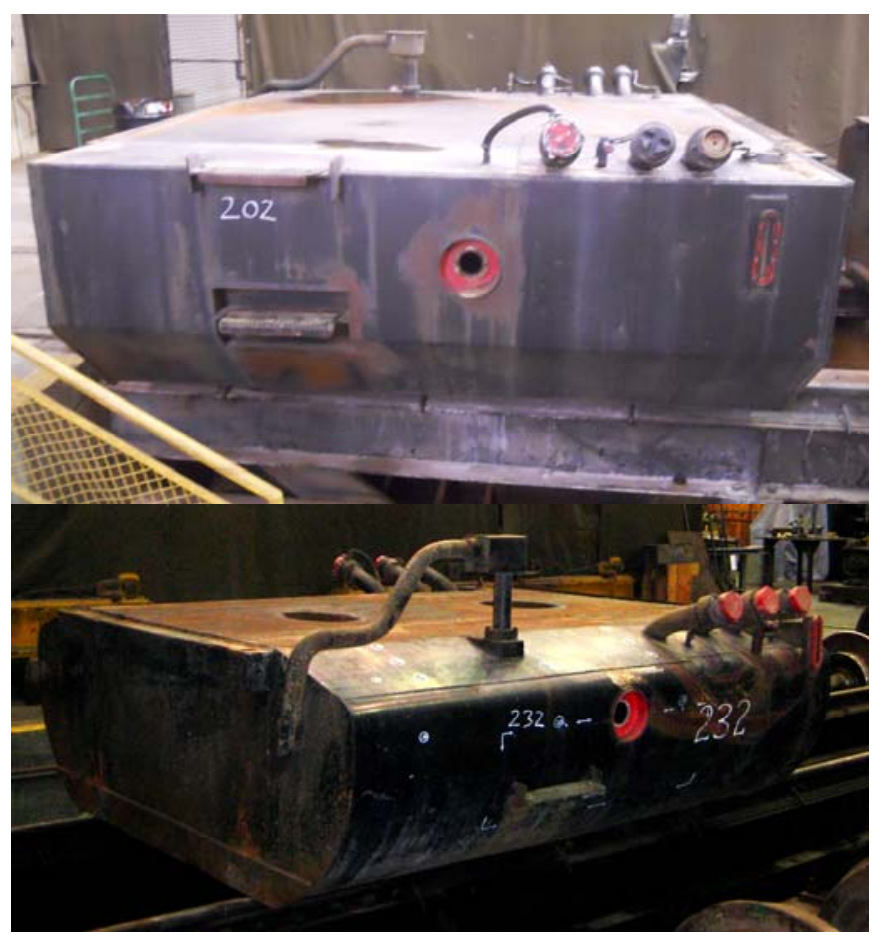

Figure 3. Fuel Tank 202 (top) and 232 (bottom)

Detailed information on the geometry of the two fuel tanks has been provided by TTCI. This information includes the overall dimensions of the tanks, the thicknesses of the sheets making up the exterior of the tanks, the placement of the lateral and longitudinal baffles in the tanks' interiors, the thickness of the baffles, and the arrangement of holes and cutouts within the baffles.

Hardness measurements were used to estimate the yield and ultimate strengths of most materials in each fuel tank. The material and thickness properties shown in Table 3 were used as inputs to the FE models. Thickness and/or hardness could not be measured for all areas of the tank prior to the test. The underlined values in Table 3 indicate such estimated values. Following the test, material coupons from the fuel tank will be cut and subjected to tensile tests to determine the stress-strain behaviors. If necessary, the pre-test FE models will be updated with these properties.

Table 3. Material Properties Used in FE Models

\begin{tabular}{|c|c|c|c|c|c|c|c|c|c|c|}
\hline Tank & \multicolumn{5}{|c|}{232} & \multicolumn{5}{|c|}{202} \\
\hline \multirow{2}{*}{ Section } & Hardness & Yield & Ultimate & Yield/Ultimate & Thickness & Hardness & Yield & Ultimate & \multirow{2}{*}{$\begin{array}{l}\text { Yield/Ultimate } \\
\text { Ratio }\end{array}$} & Thickness \\
\hline & (Brinnell) & (ksi) & (ksi) & & \begin{tabular}{|l|} 
(inches) \\
\end{tabular} & (Brinnell) & (ksi) & (ksi) & & (inches) \\
\hline Top & 110 & 36 & 56.7 & 0.65 & 0.2 & 85 & \begin{tabular}{|l|}
28.3 \\
\end{tabular} & 43.8 & 0.65 & 0.214 \\
\hline End 1 & 130 & 43.3 & 67 & 0.65 & 0.3 & 85 & \begin{tabular}{|l|}
28.3 \\
\end{tabular} & 43.8 & 0.65 & 0.4 \\
\hline End 2 & 130 & \begin{tabular}{|l|l}
43.3 \\
\end{tabular} & 67 & 0.65 & 0.3 & 85 & \begin{tabular}{|l|}
28.3 \\
\end{tabular} & 43.8 & 0.65 & 0.4 \\
\hline Side & 113 & 36 & 58.2 & 0.65 & 0.13 & 85 & \begin{tabular}{|l|}
28.3 \\
\end{tabular} & 43.8 & 0.65 & 0.22 \\
\hline Bottom & $\underline{\underline{113}}$ & 36 & 58.2 & 0.65 & 0.189 & $\underline{85}$ & \begin{tabular}{|l|}
28.3 \\
\end{tabular} & 43.8 & 0.65 & 0.214 \\
\hline $\begin{array}{l}\text { Baffles } \\
\text { (lateral) }\end{array}$ & $\underline{113}$ & 36 & 58.2 & 0.65 & 0.1875 & $\underline{85}$ & 28.3 & 43.8 & 0.65 & 0.1875 \\
\hline $\begin{array}{c}\text { Baffles } \\
\text { (longitudinal) }\end{array}$ & $\underline{113}$ & 36 & 58.2 & 0.65 & 0.25 & $\underline{85}$ & 28.3 & 43.8 & 0.65 & 0.25 \\
\hline Drain box & $\underline{110}$ & 36 & 56.7 & 0.65 & $\underline{0.5}$ & $\underline{110}$ & 36.0 & 56.7 & 0.65 & 0.5 \\
\hline
\end{tabular}


In addition to the obvious external differences between the two tanks, the internal arrangement of the baffles also differs. Previously, various baffle configurations were examined analytically to assess the relative influence of striking a tank on a baffle versus adjacent to a baffle [3]. Since that publication, TTCI has provided additional information on the internal configurations of the tanks, and the models have been updated to more accurately reflect the actual conditions within the tanks.

Tank 202 features two baffles running longitudinally (parallel to the rails) at approximately the one-third points across the width of the tank. This tank features three lateral baffles with approximately equal spacing along the length of the tank. Tank 232 also features two longitudinal baffles at approximately the one-third points across its width. However, this tank features four lateral baffles.

Figure 4 shows four images taken from the FE models of tanks 202 and 232. Note that in this figure the fuel tanks are inverted from their operating position. The left-side images show each tank's exterior. The right-side images show the baffle arrangement within each tank. In addition to having a different number of baffles, these images show that the arrangement of holes in the baffles of tank 202 also differs from the arrangement of holes in the baffles of tank 232.
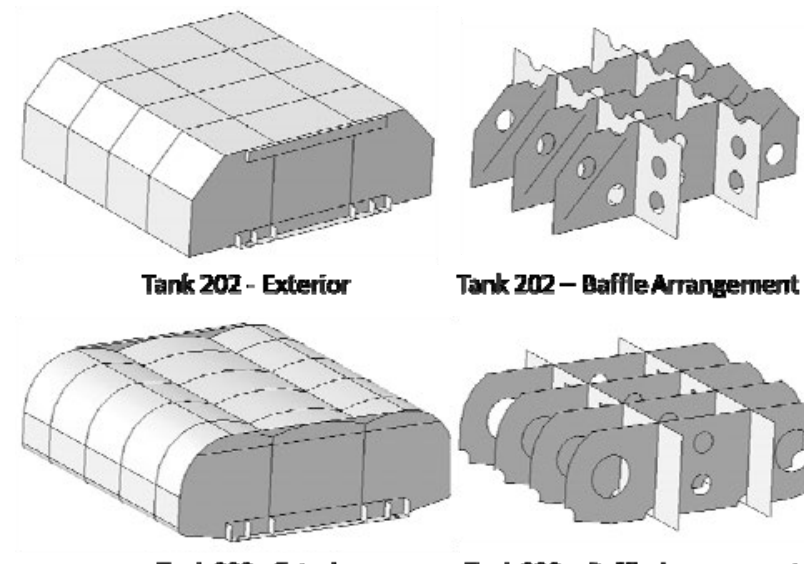

Tank 202- BaffleArrangernent

Tank 232-Exterlor

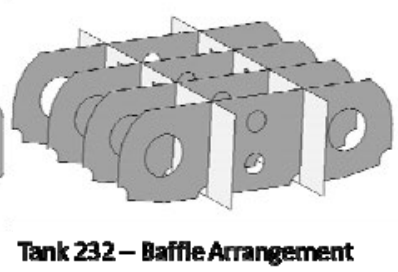

Figure 4. Exterior and Interior Views of Tanks 202 and 232

The baffle layout in each tank will affect the sequence of events during the impact test. In the current test plan, the impactor will strike each tank on its bottom face, at the tank's center. In the case of tank 202, this will place the impactor directly on top of a lateral baffle. Furthermore, this baffle features an 8-inch diameter half-circle shaped cutout at the intersection of the baffle and the bottom face sheet. Depending on the size of the impacting object, the impactor will either be smaller than the size of this cutout or large enough to span the cutout. A full-section view through the midplane of the model of tank 202 is shown in Figure 5. The baffle and its cutout are both indicated in this figure.

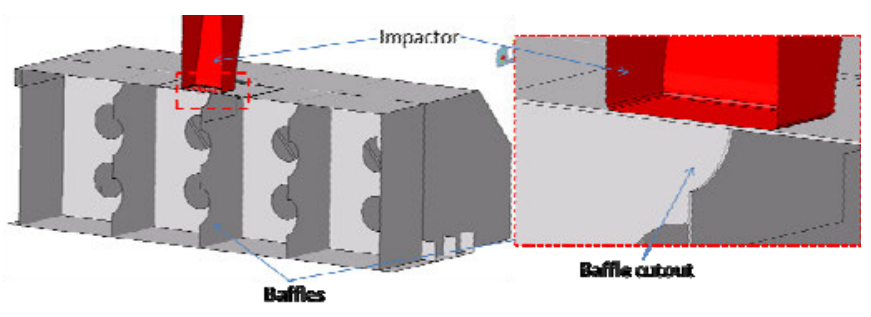

Figure 5. Tank and Impactor Arrangement for Center Impact, Tank 202

In the case of tank 232, a centered impactor will strike the tank between four baffles. The only part of the tank directly involved in the impact is the bottom sheet of the fuel tank. Additionally, because of the curved shape of the bottom of tank 232, there is initially an approximately 3 ” gap between the inner surface of the bottom sheet at the tank center and the bottom of the baffles. This gap permits fuel to flow beneath the baffles without requiring a cutout in the bottom of the baffle. Figure 6 shows a full-section view of tank 232 and the impactor. The baffles and the gap between baffles and the bottom sheet are indicated in this figure.

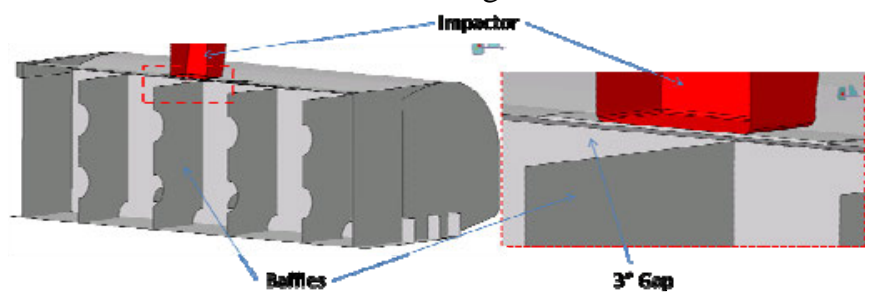

Figure 6. Tank and Impactor Arrangement for Center Impact, Tank 232

It is anticipated that the tanks will require some modification before they can be mounted to the impact wall at TTC. As seen in Figure 3, each tank features several pipes protruding from its top surface. These pipes will likely be removed from the tank to enable the top surface to be mounted about 2 inches from the impact wall, to represent the space typical in its original mounting to the locomotive underframe. As the impact is planned for the center of the tank, it is not expected that the absence of these pipes will have a large effect on the tank's behavior during the test.

\section{TEST REQUIREMENTS}

\section{Retrofit of Impact Cart}

A rail cart will be used to impact the fuel tank. During a previous testing program conducted at TTCI, an impact cart with a coil-shaped impactor was developed and used to evaluate the performance of a passenger railcar end frame [4]. This cart was fabricated from the frame of a retired ballast vibrator. The center section of the vibrator was removed and the end sections welded to each other. The cab was removed and the cart was stripped of components that were considered non-structural. Additional struts were added to ensure that the cart would act as much like a rigid body as possible. A coupler was also added to the cart frame to facilitate movement of the 
cart. The impact cart weighs approximately 14,000 pounds. The impact cart, prior to modification to accommodate the impactor, is shown in Figure 7.

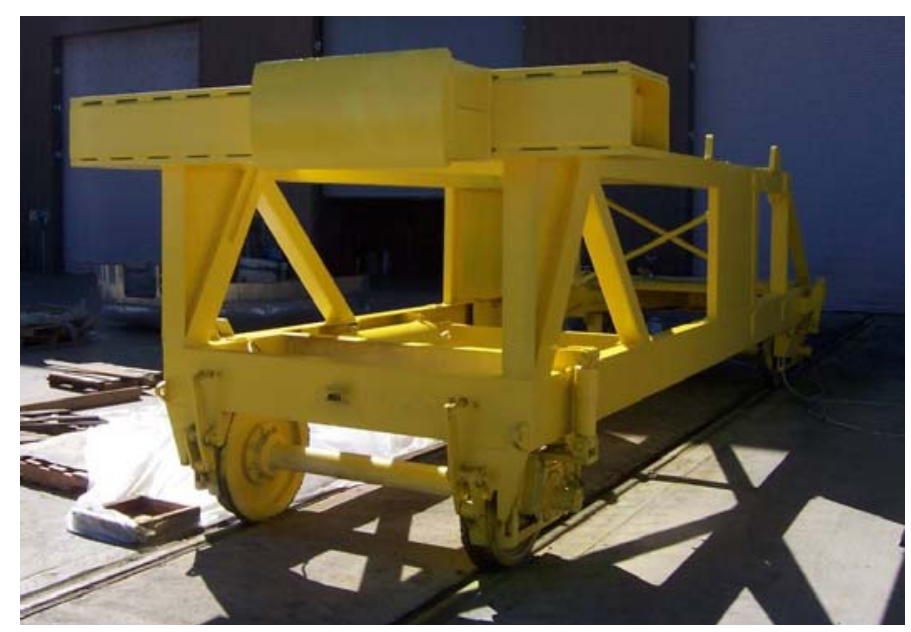

Figure 7. Impact Cart Prior to Retrofit with Impactor

TTCI has designed and built a new impactor with a square tip of 12 ” x 12" area and rectangular base of 22" x 13 ” area. The planned design of the impactor is shown in Figure 8. This impactor will be mounted onto the existing end beam of the impact cart shown in Figure 7. The attachment can be shifted laterally along the mounting face of the cart's main lateral cross-member to allow the impactor to strike the tank at the desired location.
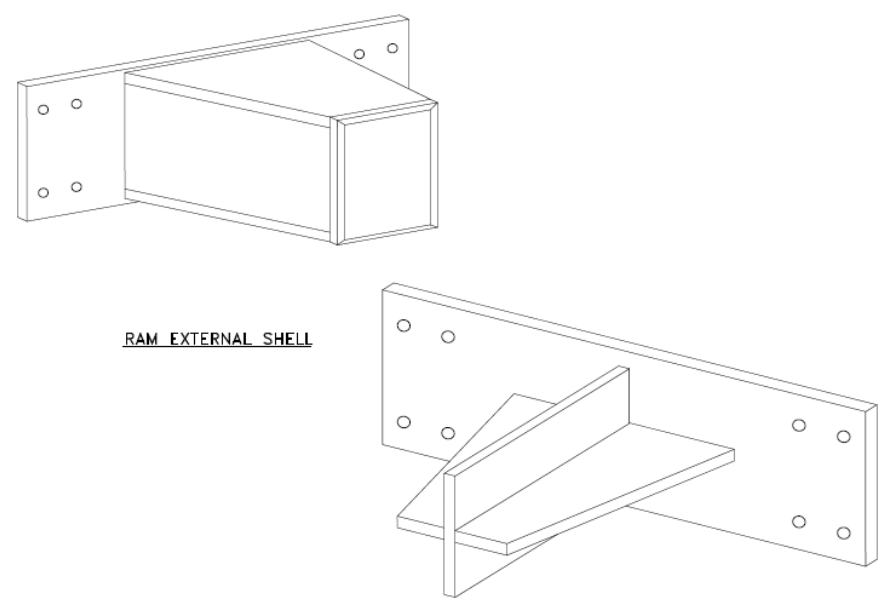

RAM INTERNAL REINFORCING

Figure 8. Images Showing Concept Impactor Construction

\section{Preparation of Impact Wall}

A fixture concept has been designed to mount the fuel tank to the crash wall at TTC. It was desired that the fuel tank mounting scheme support the fuel tank in a similar manner as the fuel tank would be supported were it still mounted to the locomotive underframe. This will give a more "natural" response to the impact, without imposing constraints on the fuel tank that would not occur in service. Two solid blocks will be attached to the test wall, simultaneously providing a standoff between the top sheet of the fuel tank and a location to weld bolts to. The tank will be attached to these bolts through the normal mounting holes at the ends of the tanks. Figure 9 shows the test setup as represented in the FE model of Tank 232.

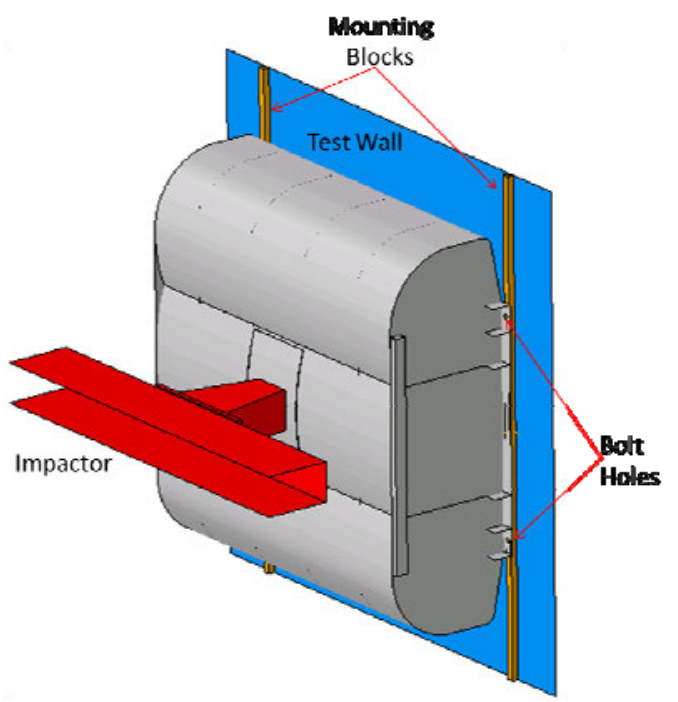

Figure 9. Test Setup in FE Model

\section{Planned Instrumentation}

Instrumentation for the impact tests will primarily be installed on the impact cart itself. The critical result from these tests will be the force-versus-displacement behavior of the tank during the impact. The impact force is planned to be derived from the longitudinal acceleration of the impact cart and the cart's mass. The displacement of the impact cart will also be derived from the measured acceleration of the impact cart.

While the impact is to occur on tangent track, tri-axial accelerometers are planned to be installed on the impact cart at its front, center, and rear ends. These accelerometers will measure the lateral and vertical behaviors of the cart should any significant non-longitudinal motions of the cart occur during the test. Additional instrumentation to be installed on the impact cart includes speed sensors to record the speed just prior to impact. As a redundant measurement, a second speed measurement is planned to be made by radar targeting the car just prior to its impact. Figure 10 shows a schematic overhead view of the impact cart and the planned instrumentation placement to be used in both tests. 

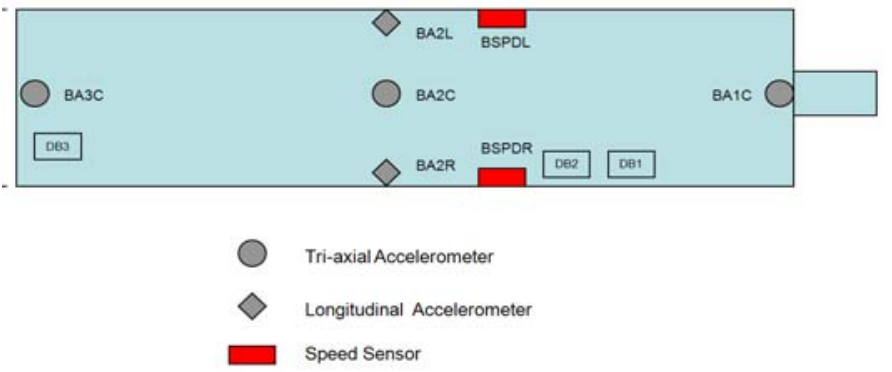

Figure 10. Schematic Showing an Overhead View of the Cart with Planned Instrumentation Placement

In addition to the instrumentation placed on the impact cart, the test will be recorded by several high- and conventional-speed cameras placed around the impact wall. The test plan calls for cameras to be placed to each side of the tank, giving a side view of the impact. Additional cameras will capture an oblique view of the impact. Finally, a camera is to be suspended by a crane over the impact area to provide a "head-on" view of the impact zone. The planned camera placement is illustrated in Figure 11, below.

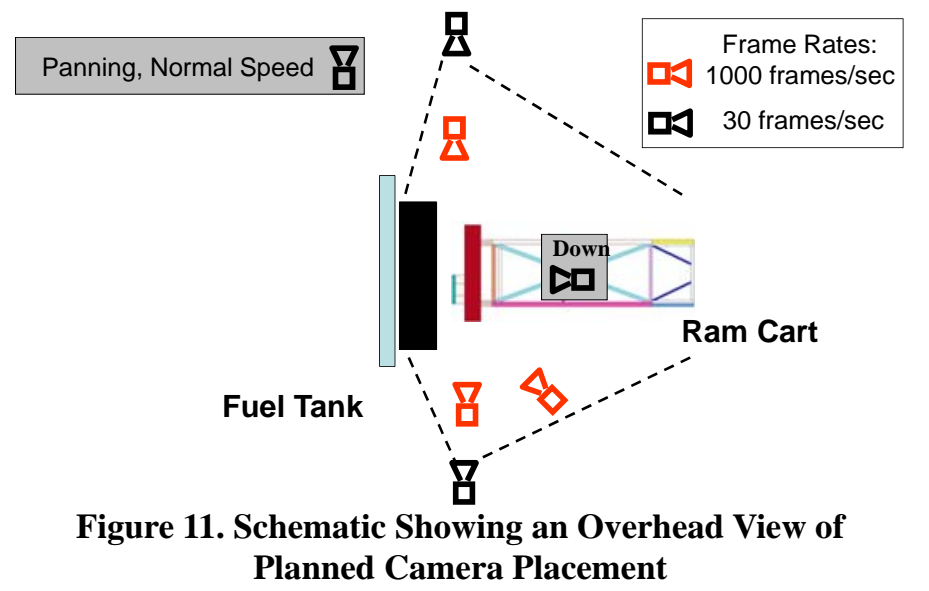

Table 4 summarizes the on-board and on-ground instrumentation and cameras planned for the two impact tests. The same arrangement of instrumentation is intended to be used in both tests, as the same test setup is being used for both tanks.

Table 4. Instrumentation for Each Impact Test

\begin{tabular}{|c|c|c|}
\hline $\begin{array}{c}\text { Measurement } \\
\text { Type }\end{array}$ & Location & Quantity \\
\hline Speed & Mounted on impactor vehicle & 2 \\
\hline Accelerometers & Mounted on impactor vehicle & 5 \\
\hline High speed video & Adjacent to track & 3 \\
\hline $\begin{array}{c}\text { Normal speed } \\
\text { video }\end{array}$ & Adjacent to track & 3 \\
\hline
\end{tabular}

\section{Target Impact Speed}

Pre-test analyses are used to predict the desired impact speed of between 5-10mph for each fuel tank. In this speed range it is predicted that the impactor will be in the puncture range for each fuel tank.

To achieve the desired impact velocity, the impact cart will be set to roll into the fuel tank mounted on the impact wall at a target impact speed. The test track leading to the impact wall is at a slight downward grade. The test cart will be let go from the appropriate distance from the wall to achieve the desired test speed from the downward slope of the track. The accuracy of achieving the impact speed is within $+/-2 \mathrm{mph}$.

\section{SUPPORTING ANALYSES}

Finite element analyses have been used to assist in planning the impact tests. FE analyses of both tanks 202 and 232 have been performed. Impact from a 12" x 12” impactor has been simulated for an impact with each tank. Additional FE analyses have been conducted on the impact cart in its current configuration. These analyses were performed both to ensure that the impact cart will not experience permanent deformation during the test as well as to assess the likelihood that the cart will lift off of the rails during the impact test.

\section{Tank Analyses}

The geometry measurements provided by TTCI have been used to construct FE models of tanks 202 and tank 232. Each tank has then been subjected to an impact by a $12 \times 12$-inch impactor of TTCI's design. The impactor in the FE model has a mass that corresponds to the estimated 14,000 pound weight of the impact cart.

The commercial finite element solver Abaqus/Explicit has been used to simulate the impacts [5]. The tanks have been meshed primarily using shell elements. The majority of the shell elements are 4-node quadrilateral elements, with some 3node triangular shells. Solid elements are included in the region beneath the impactor to facilitate element degradation and failure.

The models include elastic-perfectly plastic material properties. To provide an estimation of the energy necessary to puncture the tanks, element stiffness begins to degrade when $40 \%$ plastic equivalent strain is reached. This value was chosen assuming the material making up the fuel tanks is fairly ductile, based upon the low strengths estimated from the hardness data collected. element deformation continues beyond this amount of strain, the element will fail and be removed from the analysis. Further discussion of the material properties used in this model can be found in reference [3].

Because element degradation and failure are being employed in this model, solid (hexahedral) elements were used in place of shell elements in the area directly beneath the impactor. For both tank meshes, solid patches have 2 elements through the thickness of the sheet. The solid patch is meshed such that the elements are approximately cubes, with a 1:1:1 aspect ratio. Solid elements were used to be able to effectively incorporate failure due to material shear, which would act in 
the normal direction to a shell element under these impact conditions. The Abaqus software includes a feature, called "shell-to-solid coupling" (SSC), which generates a set of internal constraint equations at the transition between the solid mesh and shell mesh. In this research program, SSC allowed a fine, solid mesh to be used in the impact zone while a more coarse shell mesh was used to model the remainder of the fuel tank that was not expected to experience element removal. A similar technique of failure modeling, using a more advanced failure initiation criterion, was previously used in FRA's tank car research program [6].

For both tanks, the solid mesh includes the bottom sheet of the fuel tank. Because this surface makes up the outer boundary of the fuel tank, removal of elements in the bottom sheet is assumed to cause a loss of fuel in a full tank. Therefore, the tank integrity is assumed to have been compromised when elements are removed from the bottom sheet. The solid patch on tank 232 measures approximately 23 inches by 36 inches.

In the mesh of tank 202, additional solid elements are required to mesh the baffle directly beneath the impactor. A zone of elements on the baffle, directly adjacent to the bottom sheet, is meshed with solid elements. The solid patch on the bottom sheet of tank 202 is approximately 28 inches by 30 inches. The additional patch of solid elements on the baffle directly beneath the impact zone measures 20 inches wide by 8 inches high. The patches of solid elements used in both tanks are shown in Figure 12.
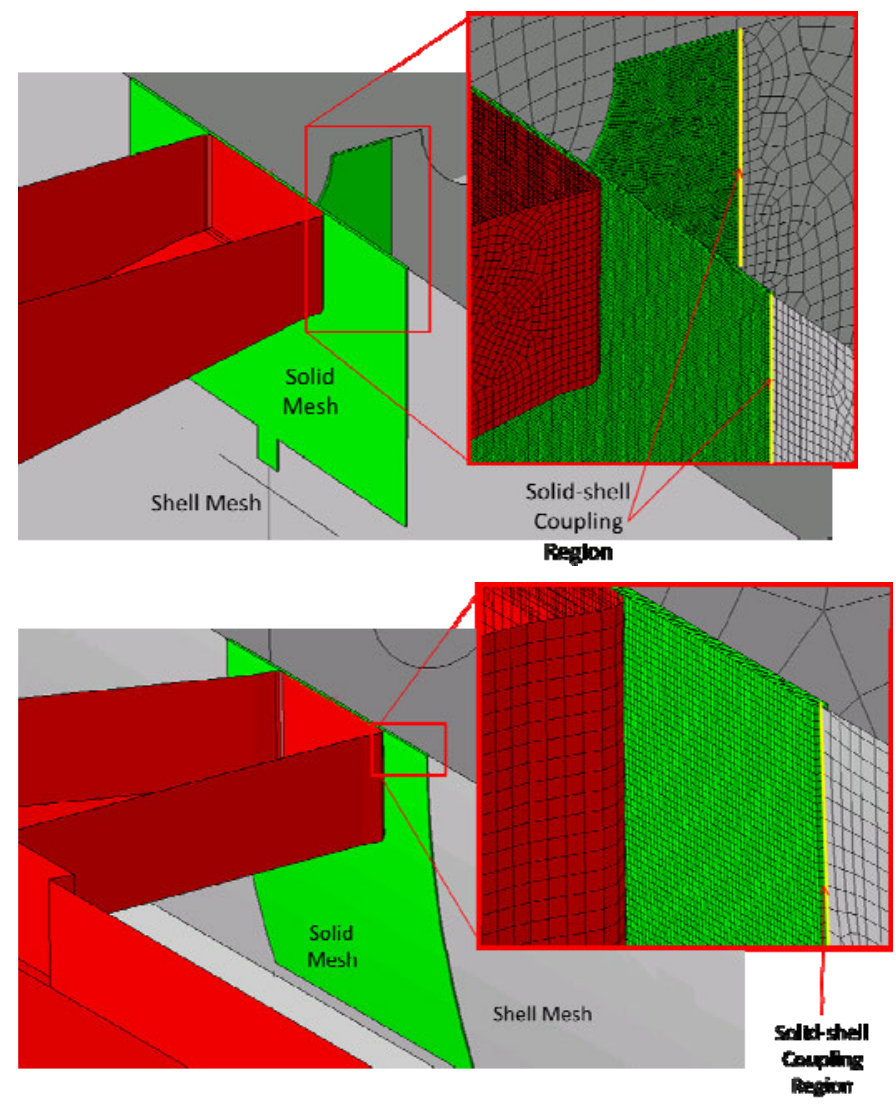

Figure 12. Solid Mesh on Tanks 202 (top) and 232 (bottom)
For all impact simulations, the tank was positioned with its top surface adjacent to the two rigid blocks acting as standoffs from the wall. Additional constraint was placed on the tank by preventing any motion of the bolt holes at the four corners of the tanks. This set of conditions represents the tank bolted to the rigid wall, which is similar in concept to the planned arrangement of the tank attachment to the wall for the impact tests.

\section{Test Cart Analyses}

A finite element (FE) model of the impact cart has been generated in HyperMesh 11.0, as shown in Figure 13 [7]. FE analyses were conducted using Abaqus to determine the mode of deformation of the cart to confirm that the cart can withstand an impact with the fuel tanks without permanent deformation. The cart FE model may also be used in analyses to determine the gross motions of the cart as a result of the impact, particularly to determine whether the impact may result in cart derailment.

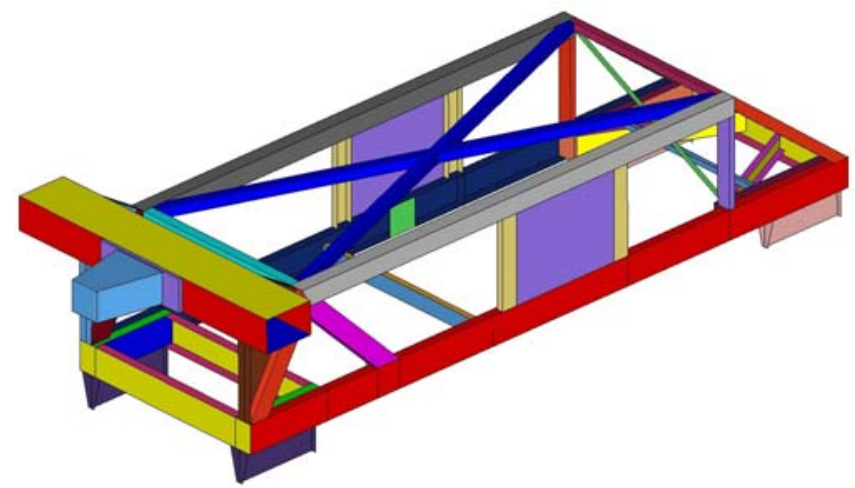

Figure 13. Finite Element Model of Impact Cart Mounted with 12" by 12" Impactor

\section{Results of Tank Analyses}

Tanks 202 and 232 were simulated to determine their response to an impact from a rigid, 14-kip 12" x 12" impactor. The impactor was given an initial longitudinal velocity of 10 mph for both tank impacts. The impactor was constrained to only have longitudinal motion. However, the restraint forces necessary to prevent vertical or lateral motion of the impactor were calculated in the model. These reaction forces were then used as inputs to the analysis of the impact cart to determine its response to the impacts.

For both tanks, a $10 \mathrm{mph}$ impact resulted in elements being removed from the bottom sheet, meaning that the tank was punctured. Due to concerns associated with conducting the test at a speed greatly above the puncture speed, each simulation was then re-run at $5 \mathrm{mph}$, a speed closer to the estimated puncture velocity.

The force-versus-displacement characteristics for tank 232 in both the $5 \mathrm{mph}$ and $10 \mathrm{mph}$ impact cases are shown in Figure 14. Only the first six inches of the responses are shown in this figure to focus on the behavior up to and just beyond puncture. The features of the two characteristics are very similar qualitatively for the two impact speeds. In both impact cases, the tank offers a slightly increasing resistance to 
displacement up to approximately 3 inches of impactor travel. At this displacement, the bottom sheet of the fuel tank has closed the gap between itself and the bottom of the baffles. The force-displacement behavior has an increased slope at this point, as the sheet has a stiffer response owing to contact with the baffles. The force-displacement behavior continues on this near-constant slope until element degradation and removal of elements in the bottom sheet occurs after approximately 5 inches of travel. In the case of the $5 \mathrm{mph}$ impact, the impactor is completely stopped and rebounds from the tank as the elastic energy imparted to the tank is recovered. The $10 \mathrm{mph}$ impactor continues to puncture the bottom sheet of the tank until the beam on the impact cart to which it is attached contacts the tank.

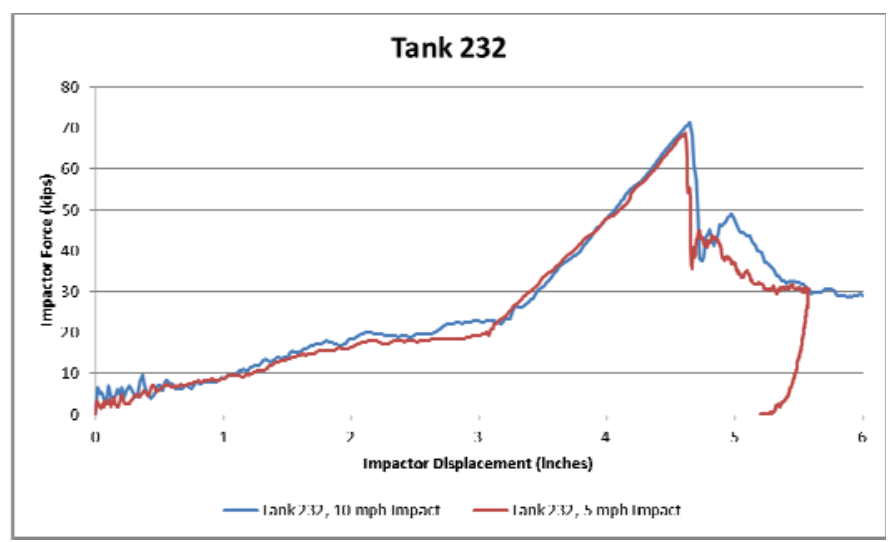

Figure 14. Force-displacement Characteristics for Tank 232

Figure 15 shows the deformed shape of tank 232 shortly after puncture has begun to occur (i.e. elements have begun to be removed from the solid patch). The contours are magnitude of displacement, in inches.

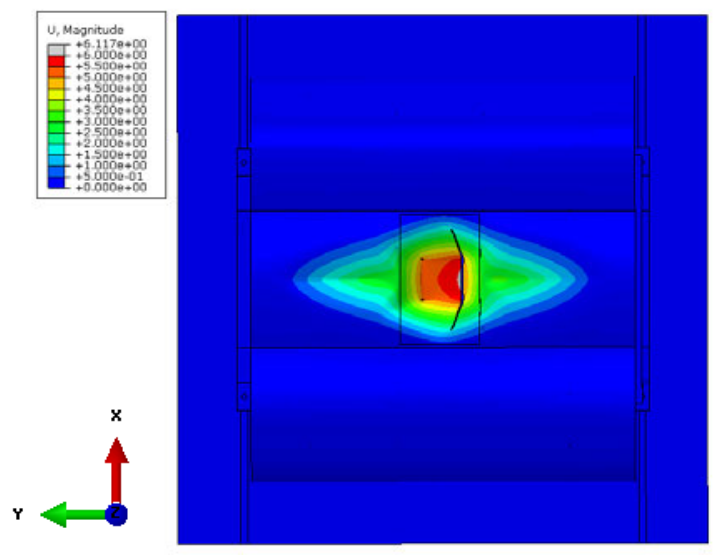

Figure 15. Deformed Shape of Tank 232 after 5 mph Impact

The force-versus-displacement characteristics for tank 202 in both the $5 \mathrm{mph}$ and $10 \mathrm{mph}$ impact cases are shown in Figure 16. This graph is limited to the first six inches of the impact response to focus on the behavior of the tank up to and slightly beyond expected puncture. These two characteristics are generally of the same shape. Initially, the tank's response to the impact from the $12 \times 12$ impactor results in a peak force of more than 30 kips. This peak is likely caused by an initial loading of the baffle directly beneath the impact zone. As the baffle deforms and buckles, the impact is spread over the outer surface of the bottom sheet of the tank. At a displacement of just over 2 inches, the bottom sheet adjacent to the center baffle begins to tear. The force drops, but because the baffle behind the bottom sheet is still in contact with the bottom sheet the force does not drop completely as the $10 \mathrm{mph}$ impactor continues to travel. The $5 \mathrm{mph}$ impactor has been stopped before the impactor travels 4 inches into the tank.

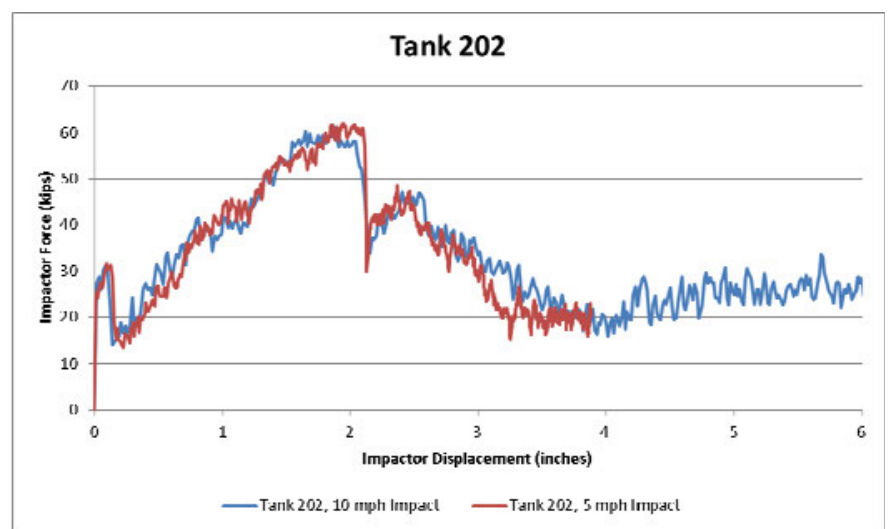

Figure 16. Force-displacement Characteristics for Tank 202

Tank 202's force-displacement behavior is generally at a higher load level than tank 232's force-displacement behavior. However, tank 202 experiences less indentation than tank 232 when failure of the outer sheet occurs. In tank 202, tearing of the bottom sheet begins to occur directly adjacent to the baffle. This tearing continues to move across the impact zone as the impactor causes a larger indentation in the bottom sheet. Eventually, the bottom sheet proceeds to tear around the perimeter of the impactor and the force level drops.

Figure 17 shows the deformed shape of tank 202 shortly after puncture has begun to occur (i.e. elements have begun to be removed from the solid patch). The contours are magnitude of displacement, in inches.

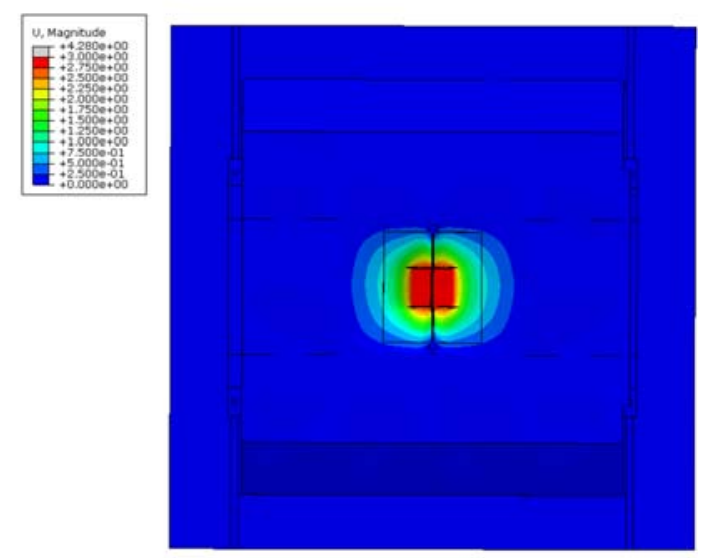

Figure 17. Deformed Shape of Tank 202 after 5 mph Impact 
A summary of the preliminary results for Tank 202 and Tank 232 are presented in Table 5. These results should be considered preliminary estimates of the behavior of the tanks. While the geometry for each tank is known, the material properties (stress-strain behavior, elongation at failure, etc.) have been estimated in these model results. Following completion of the two impact tests, material coupons will be cut from each tank and tested for their properties. The models will be updated with the actual material properties and re-run to more closely approximate the actual tanks that were tested.

Table 5. Estimated Puncture Velocities for Both Tanks

\begin{tabular}{|c|c|c|c|c|c|}
\hline Tank & $\begin{array}{c}\text { Impactor Size } \\
\text { inch } \mathrm{x} \text { inch }\end{array}$ & $\begin{array}{c}\text { Impactor Weight } \\
\text { kips }\end{array}$ & $\begin{array}{c}\text { Impactor Speed } \\
\text { mph }\end{array}$ & $\begin{array}{c}\text { Initial Kinetic Energy } \\
\text { foot-pounds }\end{array}$ & $\begin{array}{c}\text { Estimated Puncture Speed } \\
\text { mph }\end{array}$ \\
\hline 232 & $12 \times 12$ & 14 & 10 & 46,760 & 4.5 \\
\hline 232 & $12 \times 12$ & 14 & 5 & 11,690 & 4.3 \\
\hline 202 & $12 \times 12$ & 14 & 10 & 46,760 & 3.6 \\
\hline 202 & $12 \times 12$ & 14 & 5 & 11,690 & 3.7 \\
\hline
\end{tabular}

\section{SUMMARY}

FRA is sponsoring research into fuel tank crashworthiness performance. A series of dynamic impact tests are planned to evaluate the performance of fuel tanks under two loading conditions: a blunt impact and a raking impact. A variety of fuel tank designs will be tested. These tests will measure the force-deflection behavior and document the progression of deformed shape caused by the impactor. Computer models are being developed to support testing plans and conduct some parametric studies of fuel tank impacts.

The first set of preliminary fuel tank tests is planned for October 2013 at TTC. Two passenger locomotive fuel tanks will be impacted by an impactor to simulate a blunt impact loading condition. Instrumentation will be used to measure the force-deflection characteristic of each fuel tank. These tests will be used as "shakedown" tests to evaluate the test and instrumentation setup. Information learned during these two tests will be used to guide future tests of alternatively-designed passenger locomotive and DMU fuel tanks.

Fuel tank research is focused on understanding the performance of fuel tanks during collision scenarios. Results of the research will lead to development of improved protection strategies for both conventional and DMU fuel tanks.

\section{ACKNOWLEDGEMENTS}

The fuel tank research is part of the Equipment Safety Research Program sponsored by the Office of Research and Development of the FRA. Melissa Shurland, Program Manager, Office of Railroad Policy and Development, manages this research effort. Jeff Gordon, Program Manager, Office of Railroad Policy and Development, provides technical advice and logistical support. Kevin Kesler, Chief, Equipment and Operating Practices Division, reviewed and supported this effort. Luis Maal, Resident Engineer Program Manager at TTC, coordinates effort between FRA, Volpe and TTCI.

The authors would like to acknowledge Volpe Center colleagues, David Tyrell and Benjamin Perlman for their ongoing technical advice and support in the research discussed in this paper and Laura Sullivan for her assistance with test plans.

\section{REFERENCES}

[1]. U.S. Department of Transportation, Federal Railroad Administration, Code of Federal Regulations, Title 49, Part 238, Appendix D- "Requirements for External Fuel Tanks on Tier I Locomotives".

[2]. Jacobsen, K., "Fuel Tank Crashworthiness: Loading Scenarios," American Society of Mechanical Engineers, Paper No. JRC2011-56077, March 2011.

[3]. Jacobsen, K., Llana, P., Carolan, M., Sullivan, L., "Fuel Tank Integrity Research: Fuel Tank Analyses and Test Plans," Proceedings of the 2013 ASME/IEEE/ASCE Joint Rail Conference, JRC2013-2425, April 2013.

[4]. Muhlanger, M., Llana, P., Tyrell, D. "Dynamic and QuasiStatic Grade Crossing Collision Tests," American Society of Mechanical Engineers, Paper No. JRC2009-63035, March 2009.

[5]. Abaqus version 6.12. Dassault Systems Simulia Corp, Providence, RI, 2012.

[6]. Tang, Y.H., Yu, H., Gordon, J.E., Jeong, D.Y., "Finite Element Analyses of Railroad Tank Car Head Impacts," Proceedings of the 2008 ASME Rail Transportation Division Fall Technical Conference, RDTF2008-74022, September 2008.

[7]. Hypermesh version 11.0, Altair Engineering, Inc., Troy, MI, 2013. 